The Integrated Mind 


\section{The Integrated Mind}

\section{Michael S. Gazzaniga and Joseph E. LeDoux}

Department of Neurology

The New York Hospital

Cornell University Medical College

Springer Science+Business Media, LLC 


\section{Library of Congress Cataloging in Publication Data}

\section{Gazzaniga, Michael S}

The integrated mind.

Includes bibliographical references and index.

1. Intellect. 2. Split brain. I. LeDoux, Joseph, joint author. II. Title. [DNLM: 1. Corpus callosum. 2. Neurophysiology. WL307 G291i] QP398.G39

First Printing - March 1978

Second Printing - April 1979

Third Printing - January 1981

ISBN 978-1-4899-2208-3

ISBN 978-1-4899-2206-9 (eBook)

DOI 10.1007/978-1-4899-2206-9

() 1978 Springer Science+Business Media New York

Originally published by Plenum Press, New York in 1978

Softcover reprint of the hardcover 1st edition 1978

All rights reserved

No part of this book may be reproduced, stored in a retrieval system, or transmitted, in any form or by any means, electronic, mechanical, photocopying, microfilming, recording, or otherwise, without written permission from the Publisher 
To DIANA 


\section{Preface}

In this book we are trying to illuminate the persistent and nagging questions of how mind, life, and the essence of being relate to brain mechanisms. We do that not because we have a commitment to bear witness to the boring issue of reductionism but because we want to know more about what it's all about. How, indeed, does the brain work? How does it allow us to love, hate, see, cry, suffer, and ultimately understand Kepler's laws?

We try to uncover clues to these staggering questions by considering the results of our studies on the bisected brain. Several years back, one of us wrote a book with that title, and the approach was to describe how brain and behavior are affected when one takes the brain apart. In the present book, we are ready to put it back together, and go beyond, for we feel that split-brain studies are now at the point of contributing to an understanding of the workings of the integrated mind.

We are grateful to Dr. Donald Wilson of the Dartmouth Medical School for allowing us to test his patients. We would also like to thank our past and present colleagues, including Richard Nakamura, Gail Risse, Pamela Greenwood, Andy Francis, Andrea Elberger, Nick Brecha, Lynn Bengston, and Sally Springer, who have been involved in various facets of the experimental studies on the bisected brain described in this book. Thanks also to Ellen Friedman, who suffered through the typing and retyping. Finally, and most importantly, our profound thanks to the patients who continue to give their time and energy to our enterprise. They have taught us a lot more about life than we have been able to set forth in this book.

New York, N.Y.

Michael S. Gazzaniga and Joseph E. LeDoux 


\section{Contents}

1. The Split Brain and the Integrated Mind 1

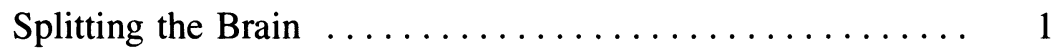

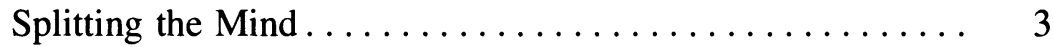

The Split Brain in Transition ................. 6

Opportunities for Validation and Theoretical Advances: The

Wilson Series $\ldots \ldots \ldots \ldots \ldots \ldots \ldots \ldots \ldots$

References .......................... 7

2 - The Nature of Interhemispheric Communication 9

What Transfers and Why? ................... 9

The Commissural Sensory Window: Its Scope and Limits 11

What Else Transfers? ...................... 13

The Role of Duplication................... 17

Where? Clues to Basic Principles ............... 19

Visual Transfer: Variability, Specificity, and Plasticity in

Brain Organization .................... 19

The Human Anterior Commissure: Individual Differences in Visual Transfer ..................... 20

Comparative Variability in the Transfer Mechanism .... 23

Neural Specificity ....................... 27

Laterality Effects in Somesthesis: Clues to Somatosensory

Organization, Cuing Strategies, and

Shifting Circuits ..................... 29

Somatosensory Organization $\ldots \ldots \ldots \ldots \ldots \ldots \ldots .30$

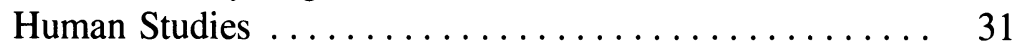

Animal Studies ....................... 36

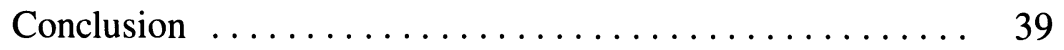

References ........................... 39 
3 - Cerebral Lateralization and Hemisphere Specialization: Facts and Theory 45

Cerebral Lateralization: The Facts ............... 46

Hemisphere Specialization ................... 47

Manipulospatial Aspects of Cerebral Lateralization ....... 49

The Nature of Manipulospatial Activities .......... 55

The Neural Substrate of Manipulospatiality ......... 56

The Language-Manipulospatial Relationship ........ . 59

Competition for Synaptic Space ............... 60

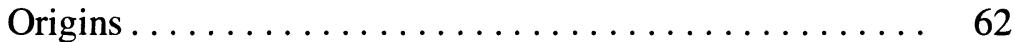

Perceptual Processing and Cerebral Lateralization ....... 63

Split-Brain Studies .................... 64

Normal Studies .......................... 67

Clinical Studies of Visual Recognition ........... 68

Loose Ends ............................ 69

Conclusions ......................... 71

References........................ 72

4. Brain and Language 77

Language Development and Lateralization .......... 78

Right-Hemisphere Language in the Left-Dominant

Population?..................... 83

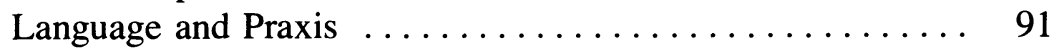

Artificial and Natural Language ................. 92

Psycholinguistics and the Brain Sciences ........... 96

Language and Memory ...................... 97

References ........................... 98

5. Brain and Intelligence 103

Cortical Equipotentiality and Interhemispheric Dynamics ... 103

Mass Action ........................... 104

How Smart Is the Half-Brain? . . . . . . . . . . . . . 105

Cognitive Cost of Commissurotomy . . . . . . . . . . . 109

The Neurology of Intelligence . . . . . . . . . . . . 115

References .......................... 117 
6. Brain, Imagery, and Memory 121

How Visual Is Visual Imagery? ............... 121

Memory ............................. 124

Basic Issues in Learning and Memory: Errors, Rewards, and Motives ..................... 125

Multiple Neural Coding ................... 130

Multidimensionality of Experience and Information Storage 132

Implications for a Theory of Memory . . . . . . . . . 135

References ......................... 138

7. On the Mechanisms of Mind 141

Split Consciousness ...................... 142

Verbal Attribution and the Sociology of Mind ......... 146

Emotion and Consciousness .................. 151

Why the Need for Consonance? ................ 155

Cross-Cuing ........................ 157

Developmental Aspects .................. 158

The Multiple Self and Free Will ............... 159

References .......................... 161

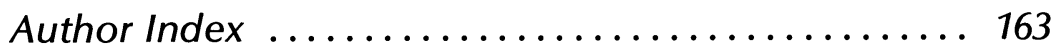

Subject Index .......................... 167 